\title{
Association Between Sodium Density and Grip Strength Among Older Korean Adults: A Nationwide Cross-Sectional Study
}

This article was published in the following Dove Press journal: Clinical Interventions in Aging

\author{
Hye-Mi Noh (D) \\ Yong Soon Park $\mathbb{D}^{2}$ \\ Hae-Jeung Lee $\mathbb{D}^{3}$ \\ Yong Kyun Roh (iD) ${ }^{4}$ \\ Hong Ji Song (D) \\ 'Department of Family Medicine, Hallym \\ University Sacred Heart Hospital, \\ Anyang, Gyeonggi-Do, Republic of Korea; \\ ${ }^{2}$ Department of Family Medicine, \\ Chuncheon Sacred Heart Hospital, \\ Hallym University College of Medicine, \\ Chuncheon, Republic of Korea; \\ ${ }^{3}$ Department of Food \& Nutrition, \\ College of Bionano, Gachon University, \\ Seongnam, Gyeonggi-Do, Republic of \\ Korea; ${ }^{4}$ Department of Family Medicine, \\ Kangnam Sacred Heart Hospital, Seoul, \\ Republic of Korea
}

Correspondence: Hong Ji Song Department of Family Medicine, Hallym University Sacred Heart Hospital, Hallym University, Anyang, Gyeonggi-Do 43I-796,

Republic of Korea

$\mathrm{Tel}+82-3 \mathrm{I}-380-3805$

Fax +82-3I-380-I782

Email hongjisong5@gmail.com

Yong Kyun Roh

Department of Family Medicine, Kangnam

Sacred Heart Hospital, Seoul I50-950,

Republic of Korea

$\mathrm{Tel}+82-2-829-5 \mathrm{I} \mid 4$

Fax +82-2-849-4469

Email rohyk@hallym.ac.kr
Purpose: Handgrip strength is a key diagnostic criterion for sarcopenia, and sodium is an essential mineral for muscle contraction. We investigated the association between grip strength and sodium intake using sodium density.

Patients and methods: A total of 2982 older adults (aged $\geq 65$ years) from the 2014-2016 Korea National Health and Nutrition Examination Survey were included. Dietary intake was assessed by a $24 \mathrm{hr}$ dietary recall, and grip strength was measured using a digital grip strength dynamometer. Based on the recommendation of the Asian Working Group for Sarcopenia, low grip strength (dynapenia) was defined as $<26 \mathrm{~kg}$ for men and $<18 \mathrm{~kg}$ for women. Multivariable logistic regression was performed to estimate the adjusted odds ratio (OR) and 95\% confidence interval (CI) and to investigate the association between the quartiles of sodium per calorie (mg/1000 kcal; sodium density) and dynapenia.

Results: A total of 577 subjects (19.3\%) had dynapenia. Subjects in the second quartile of sodium density had the lowest prevalence of dynapenia and were defined as the reference group. Among women, those in the highest quartile of sodium density showed a significantly higher risk for dynapenia (OR 1.51,95\% CI 1.10-2.07). ORs in the first and third quartiles of sodium density were 1.01 (95\% CI $0.74-1.38)$ and 1.18 (95\% CI $0.89-1.58)$, respectively. However, there was no association between sodium density and dynapenia in men.

Conclusion: High sodium density was associated with dynapenia in older women. A balanced diet of minerals is important to preserve muscle strength among older adults.

Keywords: hand strength, sarcopenia, sodium

\section{Introduction}

Global life expectancy has increased with the rapid aging of the world's population. ${ }^{1}$ Sarcopenia is an age-related syndrome characterized by progressive and generalized loss of muscle mass, muscle strength, and physical performance. ${ }^{2}$ It leads to harmful health outcomes, including falls, functional decline, and higher mortality rate in older adults. ${ }^{3}$ Dynapenia, a key component of sarcopenia, refers to the age-related loss of muscle strength, which reduces muscle quality and neuromuscular control. ${ }^{4}$ Among the methods for measuring muscle strength, handgrip strength is an inexpensive, reproducible, and easy-to-implement measure of muscular fitness. Grip strength is a biomarker of aging and predicts disability, morbidity, and mortality in older adults ${ }^{5}$ independent of muscle mass. ${ }^{6}$

Nutritional status is important for muscle metabolism and malnutrition is a risk factor for sarcopenia. Existing evidence on the relationship between sarcopenia and 
diet was limited to a number of nutrients such as dietary protein and vitamin D. ${ }^{7}$ Sodium is an essential ion for nerve conduction and skeletal muscle contraction via the $\mathrm{Na} / \mathrm{K}$ pump. ${ }^{8}$ Nevertheless, only few studies have investigated the association between sodium intake and muscle health in older adults. A previous study reported that higher urinary sodium excretion, reflecting higher sodium intake, was associated with decreased muscle mass in middle-aged or older adults. ${ }^{9}$ High sodium intake may result in urinary potassium excretion, which is related to lower muscle mass. ${ }^{10}$ However, low sodium intake may have adverse effects on muscle strength, because muscle contraction requires nerve impulse, generated by the rapid influx of sodium ions into the neuron. Restriction of sodium intake adversely affects the reninangiotensin-aldosterone system and increases muscle sympathetic nerve traffic. $^{11}$

Sodium and energy intakes are highly correlated. Heavy or active subjects tend to have higher energy intake and accordingly higher sodium intake than lean or sedentary subjects. Due to the difference in energy intakes, heavy or active subjects should eat less salty foods, whereas lean or sedentary subjects may be allowed to eat more salty foods to meet the upper limit of daily sodium intake (2300 mg/day). Recent dietary guidelines have provided recommendations based on the nutrient density (ratio of nutrient to energy in diet); ${ }^{12}$ for example, the Healthy US-Style Dietary Pattern recommended $921 \mathrm{mg}$ sodium/day at $1000 \mathrm{kcal}$ to $2392 \mathrm{mg}$ sodium/day at $3200 \mathrm{kcal}$, encouraging all individuals to choose less salty foods. ${ }^{13}$ Therefore, we adopted the concept of sodium density (mg/1000 kcal) and evaluated the association between sodium density and grip strength among older Korean adults with respect to sex. We used the 2014-2016 data from the Korea National Health and Nutrition Examination Survey (KNHANES).

\section{Materials and Methods}

\section{Study Population}

Our data source, KNHANES, was a cross-sectional nationwide survey representing the general Korean population. A stratified multistage probability sampling design was used for the KNHANES, which included comprehensive information on health status, health behavior, and sociodemographic characteristics. Face-to-face interviews, including a nutrition survey, were conducted by trained interviewers at the participants' homes to gather information. Of 23,080 KNHANES participants who completed the health interview and health examination surveys from 2014 to 2016,4766 (aged $\geq 65$ years) were included. We excluded respondents with disabilities or limited daily activity $(\mathrm{n}=967)$, history of chronic renal failure $(n=11)$, missing sodium intake data $(n=287)$, and missing grip strength or body mass index (BMI) data $(\mathrm{n}=$ 519). Finally, 2982 participants were selected as the study population. The KNHANES was conducted in accordance with the Ethical Principles for Medical Research Involving Human Subjects. The 2014-2015 KNHANES was approved by the Institutional Review Board of the Korea Centers for Disease Control and Prevention (2013-12EXP-03-5C). Written informed consent was obtained from all participants when the 2014 KNHANES, 2015 KNHANES, and 2016 KNHANES were conducted. Since 2014, research using the KNHANES data has been exempted from review about research ethics based on the Bioethics and Safety Act.

\section{Data Collection}

\section{Dietary Assessment}

The dietary intake of the participants was assessed by a $24 \mathrm{hr}$ dietary recall. Actual food shapes and two-dimensional models of plates and bowls were used by trained dietitians to help the respondents recall dietary information, including food content, consumed amounts, and recipes during the last $24 \mathrm{hrs}$. Interview quality control on field was conducted throughout the survey by the Center for Nutrition Policy and Promotion at the Korea Health Industry Development Institute. ${ }^{14}$ Based on these data, intakes of nutrients and electrolytes, including sodium and potassium, sodium per calorie $(\mathrm{mg} / 1000 \mathrm{kcal})$, and ratio of sodium to potassium $(\mathrm{Na} / \mathrm{K}$ ratio) were calculated. Because energy intakes differ according to sex, body size, and physical activity level, ${ }^{15}$ we used sodium density (mg/1000 kcal) instead of daily sodium intake (mg/day) for statistical analysis. Nutrient density better reflects the difference in energy intake than daily intake. ${ }^{16}$

\section{Measurement of Grip Strength}

The primary outcomes of interest were mean grip strength and dynapenia status. Trained examiners measured grip strength using a digital grip strength dynamometer (T.K. K. 5401; Takei, Niigata, Japan). Grip strength was measured in the standing position with the forearm away from the body at the level of the thigh. Grip strengths for both hands were measured alternately for three times, totaling to six measurements with 30 seconds of rest between two measurements. The maximum value was taken as the final grip strength. According to the recommendation of the Asian Working Group for Sarcopenia, we defined low 
grip strength (dynapenia) as handgrip strength $<26 \mathrm{~kg}$ for men and $<18 \mathrm{~kg}$ for women. ${ }^{17}$

\section{Assessment of Other Variables}

Data on demographic and socioeconomic characteristics of the subjects were obtained. The demographic variables were age, sex, educational attainment, and marital status. BMI was calculated as weight in kilograms divided by height in meters squared. Waist circumference (WC) was measured to the nearest $0.1 \mathrm{~cm}$ during exhalation, using a measuring tape at the horizontal plane midway between the inferior costal margin and iliac crest at the mid-axillary line. Smoking status was classified into three categories as follows: never-smoker, exsmoker, and current smoker. We defined the subjects who had smoked at least 5 packs of cigarettes (100 cigarettes) during their lifetime and currently smoked as current smokers, whereas those who did not smoke currently were defined as ex-smokers. Alcohol drinkers were defined as subjects who consumed alcohol 1 or more times during the last year. Alcohol intake was categorized as follows: non-drinker, mild to moderate drinking, and high-risk drinking. High-risk drinking was defined as 7 or more standard drinks per drinking day and 2 or more days of drinking per week for men, and 5 or more standard drinks per drinking day and 2 or more days of drinking per week for women. ${ }^{18}$ Mild to moderate drinking was defined when the amount of alcohol consumption was less than that for high-risk drinking. A standard drink of alcohol was defined as any drink that contained $12 \mathrm{~g}$ of pure alcohol: $4.5 \mathrm{vol} \%$ in beer, $12 \mathrm{vol} \%$ in wine, $6 \mathrm{vol} \%$ in traditional Korean makgeolli, 20 vol\% in Korean soju, and 40 vol\% in whiskey. Adequate physical activity was defined as follows: aerobic exercise, more than 150 mins of moderate-intensity and/or 75 mins of high-intensity activity per week; walking activity, more than 30 mins and 5 days a week; and resistance exercise, two or more times a week. To measure the burden of disease from multiple comorbidities in older adults, ${ }^{19}$ we calculated the Charlson comorbidity index (CCI) scores. Seven major self-reported medical conditions in KNHANES were included (diabetes mellitus; chronic lung disease, such as chronic obstructive pulmonary disease or asthma; myocardial infarction; rheumatoid arthritis; chronic liver disease, such as chronic hepatitis B or C or liver cirrhosis; stroke; and cancers).

\section{Statistical Analysis}

Considering the complex sampling design of KNHANES, the weighted mean and standard error (SE), or proportion (\%) and SE of the general characteristics according to dynapenia were calculated. The continuous variables were tested for normality using the Kolmogorov-Smirnov test. Energy intake, dietary intake of sodium, potassium, protein, carbohydrate, fat, and vitamin $\mathrm{C}, \mathrm{Na} / \mathrm{K}$ ratio, and handgrip strength did not fit a normal distribution, and hence, logtransformed values were used for comparison. Student's $t$-test was used to compare continuous variables, while the chi-square test or Fisher's exact test was used to compare categorical variables. Multivariable logistic regression was performed to estimate the adjusted odds ratio (OR) and 95\% confidence interval (CI) to investigate the association between the quartiles of sodium density and dynapenia. As participants in the second quartile of sodium density showed the lowest prevalence of dynapenia, these quartiles were defined as the reference groups based on which the OR for dynapenia in each group was calculated.

First, in the logistic regression analyses, we adjusted for age, sex, and BMI. Thereafter, in the fully adjusted model, we adjusted for age, sex, BMI, smoking status, alcohol drinking, education, marital status, CCI scores, weight loss ( $>3 \mathrm{~kg}$ within the past 1 year), protein intake, total energy intake, potassium intake, and physical activity. All tests were two-sided (significance levels at $p<0.05$ ) and were conducted using PASW Statistics version 21.0 (SPSS Inc., Chicago, IL, USA).

\section{Results}

The general characteristics of dynapenia and normal grip strength groups according to sex are presented in Table 1. In the study population, 577 subjects had dynapenia, and the prevalence of dynapenia was $19.3 \%$. The prevalence of dynapenia was higher among women $(27.4 \%)$ than among men $(10.7 \%)$. The men and women in the dynapenia group were older with a lower educational level and lower rate of subjects with spouses than those in the normal group (all $p<0.001$ ). With respect to anthropometric measurement and lifestylerelated questionnaires, the subjects in the dynapenia group had lower height, weight, BMI, and WC, and there were more subjects who experienced weight loss $>3 \mathrm{~kg}$ within the past 1 year in the dynapenia group. The normal group had more alcohol drinkers and subjects who performed physical exercise, including resistance exercise, aerobic exercise, and walking physical activity. The dynapenia group had a significantly lower total energy intake, protein intake, and daily sodium and potassium intake (mg/day) than the normal group (all $p<0.001$ ). However, sodium density, (sodium intake per calorie) was lower among men with dynapenia than that in the normal group ( $p=0.006)$, whereas there was no significant difference between the groups among women 
Table I Characteristics of the Subjects

\begin{tabular}{|c|c|c|c|c|c|c|}
\hline \multirow[t]{2}{*}{ Variable } & \multicolumn{2}{|l|}{ Men } & \multirow[t]{2}{*}{ P-value } & \multicolumn{2}{|l|}{ Women } & \multirow[t]{2}{*}{ P-value } \\
\hline & $\begin{array}{l}\text { Dynapenia }^{a} \\
(n=\mid 55)\end{array}$ & $\begin{array}{l}\text { Normal } \\
(n=\mid 289)\end{array}$ & & $\begin{array}{l}\text { Dynapenia }^{a} \\
(n=422)\end{array}$ & $\begin{array}{l}\text { Normal } \\
(n=|| \mid 6)\end{array}$ & \\
\hline Age & & & $<0.001$ & & & $<0.001$ \\
\hline $65-69$ & $10.1 \%(1.5 \%)$ & $40.8 \%(1.0 \%)$ & & $15.3 \%(1.3 \%)$ & $37.6 \%(1.1 \%)$ & \\
\hline $70-74$ & $18.0 \%(2.0 \%)$ & $29.4 \%(0.9 \%)$ & & $19.9 \%(1.2 \%)$ & $34.1 \%(1.1 \%)$ & \\
\hline $75-79$ & $28.8 \%(2.5 \%)$ & $20.4 \%(0.7 \%)$ & & $30.8 \%(1.5 \%)$ & $20.2 \%(0.7 \%)$ & \\
\hline $80 \leq$ & $43.0 \%(2.8 \%)$ & $9.4 \%(0.6 \%)$ & & $33.9 \%(1.6 \%)$ & $8.0 \%(0.5 \%)$ & \\
\hline Height $(\mathrm{cm})$ & $162.01(0.29)$ & $165.67(0.11)$ & $<0.001$ & |48.78(0.19) & $152.87(0.10)$ & $<0.001$ \\
\hline Weight (kg) & $60.21(0.44)$ & $65.29(0.19)$ & $<0.001$ & $52.65(0.31)$ & $57.49(0.18)$ & $<0.001$ \\
\hline Body mass index $\left(\mathrm{kg} / \mathrm{m}^{2}\right)$ & $22.94(0.18)$ & $23.75(0.06)$ & $<0.001$ & $23.76(0.13)$ & $24.57(0.06)$ & $<0.001$ \\
\hline Waist circumference $(\mathrm{cm})$ & $84.8 I(0.4 I)$ & $86.53(0.18)$ & $<0.001$ & $83.25(0.36)$ & $84.5 I(0.2 I)$ & 0.003 \\
\hline Education attainment & & & $<0.001$ & & & $<0.001$ \\
\hline Less than middle school & $54.7 \%(3.2 \%)$ & $31.2 \%(1.0 \%)$ & & $81.2 \%(1.8 \%)$ & $60.4 \%(1.2 \%)$ & \\
\hline Middle-High school and higher & $45.3 \%(3.2 \%)$ & $68.8 \%(1.0 \%)$ & & $18.8 \%(1.8 \%)$ & $39.6 \%(1.2 \%)$ & \\
\hline Marital status & & & $<0.001$ & & & $<0.001$ \\
\hline Single/widowed/divorced & $20.9 \%(2.7 \%)$ & $10.7 \%(0.6 \%)$ & & $59.8 \%(1.8 \%)$ & $47.1 \%(0.9 \%)$ & \\
\hline Married & $79.1 \%(2.7 \%)$ & $89.3 \%(0.6 \%)$ & & $40.2 \%(1.8 \%)$ & $52.9 \%(0.9 \%)$ & \\
\hline Smoking & & & 0.554 & & & $<0.001$ \\
\hline Never smoker & $26.2 \%(2.9 \%)$ & $23.1 \%(0.9 \%)$ & & $90.9 \%(1.1 \%)$ & $96.3 \%(0.4 \%)$ & \\
\hline Ex-smoker & $56.2 \%(3.1 \%)$ & $57.4 \%(1.0 \%)$ & & $4.8 \%(0.5 \%)$ & $2.2 \%(0.3 \%)$ & \\
\hline Current smoker & $17.6 \%(2.9 \%)$ & $19.5 \%(0.8 \%)$ & & $4.3 \%(1.0 \%)$ & $1.4 \%(0.2 \%)$ & \\
\hline Alcohol & & & $<0.001$ & & & $<0.001$ \\
\hline No & $47.1 \%(3.6 \%)$ & $29.9 \%(1.0 \%)$ & & $70.2 \%(1.8 \%)$ & $57.7 \%(1.2 \%)$ & \\
\hline Mild to moderate drinking & $50.1 \%(3.6 \%)$ & $61.8 \%(1.0 \%)$ & & $29.7 \%(1.8 \%)$ & $41.8 \%(1.2 \%)$ & \\
\hline High risk drinking & $2.8 \%(1.0 \%)$ & $8.3 \%(0.5 \%)$ & & $0.1 \%(0.0 \%)$ & $0.5 \%(0.1 \%)$ & \\
\hline \multicolumn{7}{|l|}{ Physical exercise } \\
\hline Resistance exercise (>2/week) & $10.6 \%(1.6 \%)$ & $31.9 \%(1.0 \%)$ & $<0.001$ & $3.4 \%(0.9 \%)$ & $10.8 \%(0.8 \%)$ & $<0.001$ \\
\hline Aerobic exercise & $29.8 \%(2.7 \%)$ & $49.4 \%(1.0 \%)$ & $<0.001$ & $21.7 \%(1.9 \%)$ & $34.5 \%(1.1 \%)$ & $<0.001$ \\
\hline Walking physical activity & $25.8 \%(3.2 \%)$ & $46.3 \%(1.1 \%)$ & $<0.001$ & $32.4 \%(2.1 \%)$ & $40.8 \%(1.3 \%)$ & 0.001 \\
\hline Energy $(\mathrm{kcal} / \mathrm{day})^{\mathrm{b}}$ & $1703.39(36.22)$ & $2010.05(14.32)$ & $<0.001$ & $1308.60(17.03)$ & $1528.00(|| .52)$ & $<0.001$ \\
\hline Sodium intake $(\mathrm{mg} / \text { day })^{\mathrm{b}}$ & $3047.40(\mid 13.39)$ & $3899.00(51.15)$ & $<0.001$ & $2393.27(67.69)$ & $2677.78(33.50)$ & $<0.001$ \\
\hline \multicolumn{7}{|l|}{ Sodium intake $(\mathrm{mg} / \text { day })^{\mathrm{c}}$} \\
\hline QI & $39.5 \%(2.7 \%)$ & $23.6 \%(0.8 \%)$ & $<0.001$ & $35.3 \%(1.7 \%)$ & $21.5 \%(0.9 \%)$ & $<0.001$ \\
\hline Q2 & $19.6 \%(2.1 \%)$ & $25.0 \%(0.9 \%)$ & & $23.7 \%(2.0 \%)$ & $27.8 \%(0.9 \%)$ & \\
\hline Q3 & $24.9 \%(1.9 \%)$ & $24.7 \%(0.8 \%)$ & & $20.4 \%(1.3 \%)$ & $25.4 \%(0.8 \%)$ & \\
\hline Q4 & $16.1 \%(2.4 \%)$ & $26.8 \%(0.8 \%)$ & & $20.5 \%(1.4 \%)$ & $25.3 \%(0.9 \%)$ & \\
\hline Sodium density $(\mathrm{mg} / 1000 \mathrm{kcal})^{\mathrm{b}}$ & $1869.69(47.74)$ & |968.7|(21.62) & 0.006 & $1848.70(42.50)$ & $1763.93(19.76)$ & 0.426 \\
\hline Sodium density (mg//000kcal) ${ }^{d}$ & & & 0.009 & & & 0.013 \\
\hline QI & $28.1 \%(2.4 \%)$ & $19.9 \%(0.7 \%)$ & & $30.8 \%(1.5 \%)$ & $29.4 \%(1.0 \%)$ & \\
\hline Q2 & $21.4 \%(2.4 \%)$ & $26.2 \%(0.9 \%)$ & & $20.7 \%(1.4 \%)$ & $24.9 \%(0.9 \%)$ & \\
\hline Q3 & $23.3 \%(2.2 \%)$ & $25.8 \%(0.9 \%)$ & & $23.1 \%(1.4 \%)$ & $25.0 \%(0.9 \%)$ & \\
\hline Q4 & $27.2 \%(2.7 \%)$ & $28.1 \%(0.8 \%)$ & & $25.3 \%(1.7 \%)$ & $20.7 \%(0.9 \%)$ & \\
\hline
\end{tabular}

(Continued) 
Table I (Continued).

\begin{tabular}{|c|c|c|c|c|c|c|}
\hline \multirow[t]{2}{*}{ Variable } & \multicolumn{2}{|l|}{ Men } & \multirow[t]{2}{*}{ P-value } & \multicolumn{2}{|l|}{ Women } & \multirow[t]{2}{*}{ P-value } \\
\hline & $\begin{array}{l}\text { Dynapenia }^{a} \\
(n=I 55)\end{array}$ & $\begin{array}{l}\text { Normal } \\
(n=\mid 289)\end{array}$ & & $\begin{array}{l}\text { Dynapenia }^{a} \\
(n=422)\end{array}$ & $\begin{array}{l}\text { Normal } \\
(n=|| \mid 6)\end{array}$ & \\
\hline Potassium (mg/day) ${ }^{\mathrm{b}}$ & $2456.38(73.59)$ & $3146.35(32.28)$ & $<0.001$ & $1950.39(39.47)$ & $2633.25(26.01)$ & $<0.001$ \\
\hline Potassium density (mg/l000kcal) ${ }^{b}$ & |444.94(36.13) & $1582.14(\mid 1.27)$ & $<0.001$ & $1512.19(23.74)$ & $1742.10(15.87)$ & $<0.001$ \\
\hline Sodium to Potassium ratio ${ }^{\mathrm{b}}$ & $1.5 \mathrm{I}(0.05)$ & $1.33(0.02)$ & 0.384 & $\mathrm{I} .34(0.03)$ & $1.10(0.16)$ & $<0.001$ \\
\hline Sodium to Potassium ratio ${ }^{\mathrm{e}}$ & & & 0.001 & & & $<0.001$ \\
\hline QI & $15.6 \%(2.1 \%)$ & $15.4 \%(0.8 \%)$ & & $22.2 \%(1.5 \%)$ & $26.9 \%(1.1 \%)$ & \\
\hline Q2 & $17.9 \%(1.8 \%)$ & $23.9 \%(0.8 \%)$ & & $21.0 \%(1.3 \%)$ & $26.7 \%(0.9 \%)$ & \\
\hline Q3 & $39.2 \%(3.0 \%)$ & $28.1 \%(0.9 \%)$ & & $23.5 \%(1.6 \%)$ & $25.3 \%(0.8 \%)$ & \\
\hline Q4 & $27.3 \%(2.5 \%)$ & $32.6 \%(0.9 \%)$ & & $33.3 \%(1.6 \%)$ & $21.0 \%(0.8 \%)$ & \\
\hline Protein $(g / \text { day })^{b}$ & $51.69(1.37)$ & $66.09(0.59)$ & $<0.001$ & $39.75(0.68)$ & $49.06(0.47)$ & $<0.001$ \\
\hline Carbohydrate $(g / \text { day })^{\mathrm{b}}$ & $305.17(6.86)$ & $336.46(2.22)$ & $<0.001$ & $243.46(3.01)$ & $275.81(2.21)$ & $<0.001$ \\
\hline Fat $(g / \text { day })^{b}$ & $21.58(0.74)$ & $32.4 I(0.47)$ & $<0.001$ & $17.29(0.48)$ & $23.75(0.37)$ & $<0.001$ \\
\hline Vitamin C (mg/day $)^{\mathrm{b}}$ & $87.28(6.79)$ & III.32(2.24) & $<0.001$ & $65.53(2.69)$ & $\mathrm{II} 6.5(2.5 \mathrm{I})$ & $<0.001$ \\
\hline Handgrip strength $(\mathrm{kg})^{\mathrm{b}}$ & $22.08(0.25)$ & $35.93(0.11)$ & $<0.001$ & $14.83(0.08)$ & $23.13(0.06)$ & $<0.001$ \\
\hline$>3 \mathrm{~kg}$ of weight loss within past I year & $18.8 \%(1.8 \%)$ & $13.3 \%(0.7 \%)$ & 0.003 & $14.7 \%(1.3 \%)$ & $12.1 \%(0.6 \%)$ & 0.040 \\
\hline Charlson Comorbidity Index & & & 0.086 & & & 0.180 \\
\hline 0 & $70.4 \%(2.8 \%)$ & $68.2 \%(0.9 \%)$ & & $64.0 \%(2.0 \%)$ & $67.0 \%(1.0 \%)$ & \\
\hline $1-2$ & $24.8 \%(2.7 \%)$ & $28.7 \%(0.9 \%)$ & & $35.1 \%(2.0 \%)$ & $32.2 \%(1.0 \%)$ & \\
\hline$\geq 3$ & $4.7 \%(0.3 \%)$ & $3.1 \%(0.3 \%)$ & & $0.8 \%(0.0 \%)$ & $0.8 \%(0.0 \%)$ & \\
\hline
\end{tabular}

Notes: Data are means \pm standard error or an estimated percentage (standard error), as appropriate. $p$-values are those for the $t$-test for means and chi-square test or

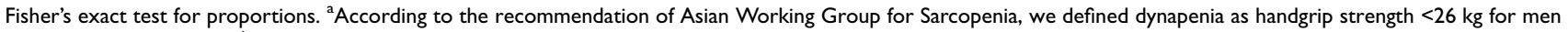
and $<18 \mathrm{~kg}$ for women. bValues are the estimated means, but log-transformed values were used for comparisons. ${ }^{\mathrm{c}}$ Men Q1 ( 2152.53$)$, Q2 (2I52.53-32।7.42), Q3 (32I7.42-4700.53), Q4 (4700.53-), Women, QI (-1420.52), Q2 (I420.52-2305.0I), Q3 (2305.0I-34I2.79), Q4 (34I2.79-) dMen, QI (-I253.I8), Q2 (I253.I8-I74I.89), Q3 (I74I.89-240I.55), Q4 (240I.55-), Women, QI (-I I I3.99), Q2 (I I I3.99-1610.93), Q3 (I6I0.93-2260.40), Q4 (2260.40-) eMen QI (-0.8452), Q2 (0.8452-I.I723), Q3 (I.I723-I.608I), Q4 (I.608I-), Women, QI (-0.7088), Q2 (0.7088-I.03I), Q3 (I.03I-I.466), Q4 (I.466-).

( $p=0.426)$. Among women, those in the dynapenia group had significantly higher $\mathrm{Na} / \mathrm{K}$ ratio than those in the normal group $(p<0.001)$. When we divided the participants into quartile groups for sodium density, the second quartile of sodium density showed the lowest prevalence of dynapenia among both men and women.

Table 2 presents the association between dynapenia and sodium density. In the total study population, the subjects in the lowest and highest quartiles of sodium density were more likely to have dynapenia than those in the reference group (second quartile) in the unadjusted model. However, after adjustment for potential confounders, subjects in the highest quartile (OR 1.39, 95\% CI 1.07-1.80) had higher odds for dynapenia than those in the reference group, whereas this association was not maintained for the lowest quartile. In men, low sodium density was associated with higher odds for dynapenia in the unadjusted model; however, the association was attenuated after adjustment for potential confounders. There was no association between sodium density and dynapenia (Figure 1). Among women, subjects in the lowest and highest quartiles of sodium density showed a higher risk for dynapenia (OR 1.47, 95\% CI 1.16-1.87; OR 1.62, 95\% CI 1.26-2.09, respectively) than those in the reference group in the unadjusted model. However, in the fully adjusted model, the lowest quartile of sodium density lost significance (OR 1.01, 95\% CI 0.74-1.38), whereas the highest quartile of sodium density showed a significantly higher risk for dynapenia (OR 1.51, 95\% CI 1.10-2.07) (Figure 2).

\section{Discussion}

In this large nationwide study, we found that sex differences existed in the association between sodium density and grip strength among older Korean adults. Among 
Table 2 The Association of Sodium Density with Dynapenia

\begin{tabular}{|c|c|c|c|c|c|c|c|c|}
\hline & \multicolumn{2}{|c|}{ Crude } & \multicolumn{2}{|c|}{ Modell } & \multicolumn{2}{|c|}{ Model2 } & \multicolumn{2}{|c|}{ Model3 } \\
\hline & OR & $(95 \% \mathrm{Cl})$ & OR & $(95 \% \mathrm{Cl})$ & OR & $(95 \% \mathrm{Cl})$ & OR & $(95 \% \mathrm{Cl})$ \\
\hline \multicolumn{9}{|l|}{ Total study population } \\
\hline \multicolumn{9}{|l|}{ Sodium density (mg//000 kcal) } \\
\hline QI (-I I77.94) & 1.53 & $(1.25-1.86)$ & 1.25 & $(1.00-1.55)$ & 1.16 & $(0.90-1.51)$ & 1.03 & $(0.79-1.35)$ \\
\hline Q2 (II77.94-1675.48) & I & & I & & I & & I & \\
\hline Q3 (1675.48-2356.22) & 1.12 & $(0.92-1.36)$ & 1.13 & $(0.93-1.37)$ & 1.13 & $(0.90-1.42)$ & 1.12 & $(0.89-I .4 I)$ \\
\hline Q4 (2356.22-) & 1.28 & $(1.04-1.58)$ & 1.45 & $(1.16-1.8 I)$ & 1.40 & $(1.08-1.82)$ & 1.39 & $(1.07-1.80)$ \\
\hline \multicolumn{9}{|l|}{ Men } \\
\hline \multicolumn{9}{|l|}{ Sodium density (mg/l000 kcal) } \\
\hline QI (-1253.18) & 1.61 & $(1.13-2.29)$ & 1.55 & $(1.07-2.25)$ & 1.16 & $(0.7 I-1.90)$ & 1.08 & $(0.68-1.72)$ \\
\hline Q2 (I253.18-174I.89) & I & & I & & I & & I & \\
\hline Q3 (1741.89-240I.55) & 1.29 & $(0.92-1.79)$ & 1.25 & $(0.87-1.78)$ & 1.28 & $(0.85-1.94)$ & 0.99 & $(0.68-1.43)$ \\
\hline Q4 (240I.55-) & 1.15 & $(0.79-1.66)$ & 1.12 & $(0.77-1.64)$ & 1.06 & $(0.68-1.66)$ & 1.15 & $(0.7 I-1.86)$ \\
\hline \multicolumn{9}{|l|}{ Women } \\
\hline Sodium density $(\mathrm{mg} / 1000 \mathrm{kcal})$ & & & & & & & & \\
\hline QI (-III3.99) & 1.47 & $(1.16-1.87)$ & 1.40 & $(1.08-1.83)$ & 1.63 & $(1.18-2.25)$ & 1.01 & $(0.74-1.38)$ \\
\hline Q2 (1II3.99-1610.93) & I & & I & & I & & I & \\
\hline Q3 (1610.93-2260.40) & 1.04 & $(0.82-1.33)$ & 1.10 & $(0.86-1.40)$ & 1.24 & $(0.93-1.65)$ & 1.18 & $(0.89-1.58)$ \\
\hline Q4 (2260.40-) & 1.62 & $(1.26-2.09)$ & 1.95 & $(1.47-2.57)$ & 1.98 & $(1.43-2.74)$ & 1.51 & $(1.10-2.07)$ \\
\hline
\end{tabular}

Notes: Modell: age, BMI. Model2: age, BMI, smoking, alcohol drinking, education, marital status. Model3: age, BMI, smoking, alcohol drinking, education, marital status, Charlson comorbidity index, $>3 \mathrm{~kg}$ of weight loss within past I year, protein intake, total energy intake, potassium intake, resistance exercise, aerobic exercise. Abbreviations: $\mathrm{Cl}$, confidence interval; OR, odds ratio.

older men, there was no significant association between sodium density and dynapenia. However, high sodium density increased the risk for low muscle strength among older women.

To the best of our knowledge, there is no direct comparable study on grip strength with respect to dietary sodium intake. A previous Korean study using data from the 2016

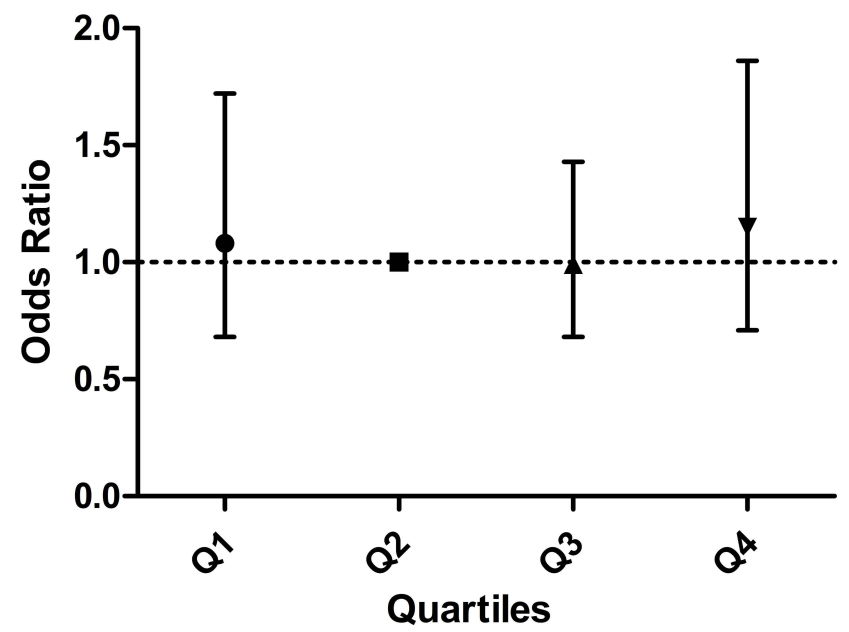

Figure I Association of sodium density with dynapenia among men.
KNHANES showed that daily intake of fiber $(\beta=0.071)$, potassium $(\beta=0.0001)$, and vitamin $\mathrm{C}(\beta=0.006)$ positively correlated with grip strength in older men and that polyunsaturated fatty acid $(\beta=0.083)$ and vitamin $C(\beta=0.003)$ showed positive association with grip strength in older women. ${ }^{20}$ However, they did not report the association between daily sodium intake and grip strength. Another

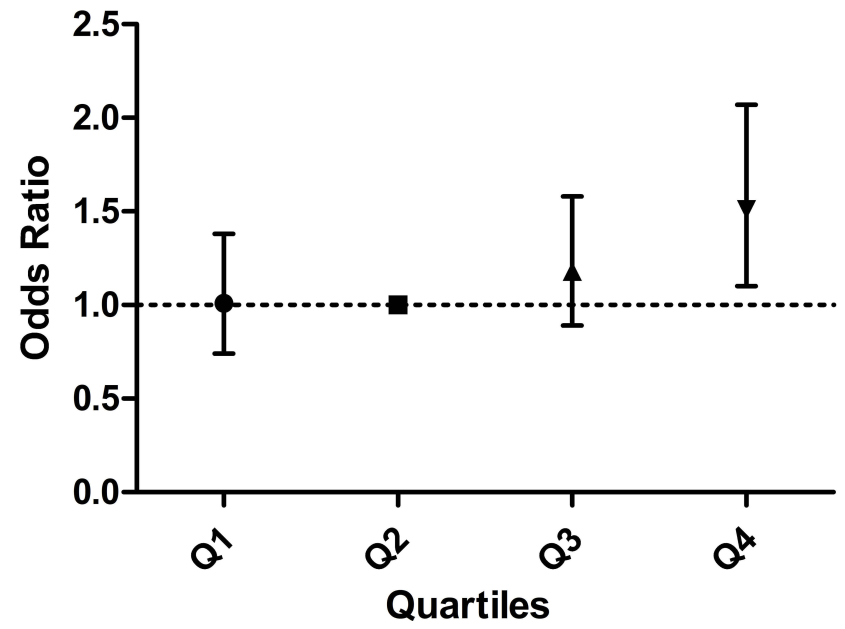

Figure 2 Association of sodium density with dynapenia among women. 
study reported that higher urinary sodium excretion was associated with decreased muscle mass in middle-aged and older Korean adults; ${ }^{9}$ however, they did not examine muscle strength or function. Muscle strength does not depend solely on muscle mass, and the relationship between muscle strength and mass is not linear. ${ }^{21}$ Low muscle strength is an essential criterion for sarcopenia. ${ }^{2}$ A recent study using Korean Frailty and Aging Cohort Study (KFACS) data, which comprises five components including low grip strength, investigated the association between daily sodium intake and frailty. The authors reported that a high sodium intake of more than $3575 \mathrm{mg}$ was associated with frailty. ${ }^{22} \mathrm{In}$ the present study, contrary to previous study, we used dynapenia as a study outcome, excluded subjects with disabilities or limited daily activity, and included relatively healthy elderly individuals in the study population. In our study, high sodium density (OR 1.51, 95\% CI 1.10-2.07) and Na/ $\mathrm{K}$ ratio (OR 1.54, 95\% CI 1.17-2.03) were significantly associated with the risk of dynapenia in older women, whereas daily sodium intake was not associated with dynapenia (Supplementary tables).

Although the influence of high sodium density on muscular fitness remains unclear, several possible mechanisms have been proposed. First, a salty diet results in excessive urinary potassium excretion. ${ }^{23}$ Muscle contraction is dependent on both sodium and potassium, and relative potassium deficiency is related to lower muscle mass. ${ }^{10}$ In this study, despite the lack of an association between daily sodium intake and dynapenia, high sodium density and $\mathrm{Na} / \mathrm{K}$ ratio had higher odds for dynapenia in older women. This suggests that sodium density and the interaction between sodium and other nutrients might be important for muscle health rather than total sodium intake.

Second, sodium may increase the risk for cardiovascular disease via increased blood pressure and endothelial dysfunction, which may decrease blood supply to skeletal muscles, leading to reduced muscle function. ${ }^{24}$ Hence, the results of secondary analysis of the Dietary Approaches to Stop Hypertension- Sodium Trial suggested that the association of sodium with blood pressure was stronger at a higher sodium density than at a lower sodium density. ${ }^{25}$ Third, a high-salt diet may result in dysregulation of the renin-angiotensin-aldosterone system, ${ }^{26}$ which may contribute to sarcopenia.

In our study, high sodium density was not associated with dynapenia among older men. Although the mechanisms for these sex-specific associations are unclear, this might be due to the differences in the mechanisms of sodium transport between the sexes. ${ }^{27}$ In addition, a recent study has reported differences in skeletal muscle fiber-type composition between the sexes, with type II fibers being dominant among men and type 1 fibers being dominant among women. ${ }^{28}$

Additionally, in this study, low sodium density was related to higher odds for dynapenia in the unadjusted model among both men and women; however, this association was weakened after adjustments for potential confounders. Recent studies have reported the relationship between low sodium intake and adverse health outcomes. A prospective cohort study suggested a J-shaped association between sodium intake and cardiovascular diseases and reported that low sodium intake and high sodium intake increased the risk for cardiovascular events. ${ }^{29}$ Further, low sodium intake was associated with poor cognitive function in community-dwelling older adults. ${ }^{30}$ Sodium is an essential ion for nerve conduction, muscle activation, and cell signaling, ${ }^{31}$ further research is required to clarify the association of sodium intake with muscle strength and to determine the mechanisms underlying this association.

Our study had several strengths. First, we used data from a large nationally representative sample, which suggest that our findings can be generalized. To our best knowledge, this is the first study to elucidate the effect of sodium density on muscle strength in older adults. Second, although we adjusted for a wide range of confounding factors, including demographic factors; lifestyle factors, such as physical activity and protein intake; and comorbidities, the results of our study remained significant.

Despite these strengths, the present study has limitations. First, this study had a cross-sectional design, which did not allow us to make causal inferences. Second, sodium intake was calculated using a single $24 \mathrm{hr}$ recall method, which might be less accurate than the food frequency questionnaire. However, a previous study reported that sodium intake obtained from $24 \mathrm{hr}$ recall correlated with those from $24 \mathrm{hr}$ urine collection. ${ }^{32}$ Third, we did not have data on serum electrolytes and could not analyze whether the study subjects took more sodium owing to their underlying hyponatremia. However, the prevalence of hyponatremia $(7 \%)$ was relatively lower in communitydwelling older adults, ${ }^{30}$ and we excluded subjects with disability or limited daily activity to minimize bias on the subjects' dietary intake according to health conditions.

\section{Conclusion}

We found a sex-specific association between sodium density and dynapenia among older Korean adults. The results showed 
that high sodium density and $\mathrm{Na} / \mathrm{K}$ ratio increased the risk for low muscle strength in older women. These results suggest that a balanced dietary intake, considering sodium and potassium as well as protein, could play significant roles in preserving muscle strength among older adults. Prospective studies, including long-term clinical trials, are needed to confirm the effect of dietary intake of sodium on muscular fitness.

\section{Abbreviations}

KNHANES, Korea National Health and Nutrition Examination Survey; BMI, body mass index; WC, waist circumference.

\section{Data Availability}

The KNHANES data can be downloaded from the web site, https://knhanes.cdc.go.kr/knhanes/main.do.

\section{Funding}

This research did not receive any specific grant from funding agencies in the public, commercial, or not-forprofit sectors.

\section{Disclosure}

The authors report no conflicts of interest in this work.

\section{References}

1. Foreman KJ, Marquez N, Dolgert A, et al. Forecasting life expectancy, years of life lost, and all-cause and cause-specific mortality for 250 causes of death: reference and alternative scenarios for 2016-40 for 195 countries and territories. Lancet. 2018;392(10159):2052-2090. doi:10.1016/S0140-6736(18)31694-5

2. Cruz-Jentoft AJ, Baeyens JP, Bauer JM, et al. Sarcopenia: european consensus on definition and diagnosis: report of the European Working Group on Sarcopenia in Older People. Age Ageing. 2010;39 (4):412-423. doi:10.1093/ageing/afq034

3. Wright JM, Beaudart C, Zaaria M, Pasleau F, Reginster JY, Bruyère O. Health outcomes of sarcopenia: a systematic review and meta-analysis. PLoS ONE. 2017;12(1):e0169548. doi:10.1371/journal.pone.0169548

4. Manini TM, Clark BC. Dynapenia and aging: an update. J Gerontol A Biol Sci Med Sci. 2012;67(1):28-40. doi:10.1093/gerona/glr010

5. Sayer AA, Kirkwood TB. Grip strength and mortality: a biomarker of ageing? Lancet. 2015;386(9990):226-227. doi:10.1016/S0140-6736(14) 62349-7

6. Gale CR, Martyn CN, Cooper C, Sayer AA. Grip strength, body composition, and mortality. Int $J$ Epidemiol. 2007;36(1):228-235. doi:10.1093/ije/dyl224

7. Beaudart C, Dawson A, Shaw SC, et al. Nutrition and physical activity in the prevention and treatment of sarcopenia: systematic review. Osteoporosis Int. 2017;28(6):1817-1833. doi:10.1007/s00198-017-3980-9

8. Clausen $\mathrm{T}$. $\mathrm{Na}+-\mathrm{K}+$ pump regulation and skeletal muscle contractility. Physiol Rev. 2003;83(4):1269-1324. doi:10.1152/physrev.00011.2003

9. Huh JH, Lim JS, Lee MY, Chung CH, Shin JY. Gender-specific association between urinary sodium excretion and body composition: analysis of the 2008-2010 Korean National Health and Nutrition Examination Surveys. Metabolism. 2015;64(7):837-844. doi:10.1016/ j.metabol.2015.03.010
10. Frassetto L, Morris RC Jr, Sellmeyer DE, Todd K, Sebastian A. Diet, evolution and aging-the pathophysiologic effects of the postagricultural inversion of the potassium-to-sodium and base-tochloride ratios in the human diet. Eur J Nutr. 2001;40(5):200-213. doi:10.1007/s394-001-8347-4

11. Grassi G, Dell'Oro R, Seravalle G, Foglia G, Trevano FQ, Mancia G. Short- and long-term neuroadrenergic effects of moderate dietary sodium restriction in essential hypertension. Circulation. 2002;106 (15):1957-1961. doi:10.1161/01.CIR.0000033519.45615.C7

12. Drewnowski A, Dwyer J, King JC, Weaver CM. A proposed nutrient density score that includes food groups and nutrients to better align with dietary guidance. Nutr Rev. 2019;77(6):404-416. doi:10.1093/ nutrit/nuz002

13. Office of Disease Prevention and Health Promotion. Nutrients in healthy US-style food pattern at each calorie level. Available from: https://health.gov/dietaryguidelines/2015-scientific-report/PDFs/ Appendix-E-3.1.pdf. Accessed August 2, 2019.

14. Ministry of Health and Welfare, Korea Centers for Disease Control and Prevention, Korea Health Industry Development Institute. Guideline for Nutrition Survey of the Korea National Health and Nutrition Examination Survey 1998-2009. Seoul: Korea Health Industry Development Institute; 2009.

15. Westerterp KR, Donkers JH, Fredrix EW, Boekhoudt P. Energy intake, physical activity and body weight: a simulation model. $\mathrm{Br}$ J Nutr. 1995;73(3):337-347. doi:10.1079/BJN19950037

16. Drewnowski A, Fulgoni VL. Nutrient density: principles and evaluation tools. Am J Clin Nutr. 2014;99(5):1223S-1228S. doi:10.3945/ ajcn. 113.073395

17. Chen LK, Liu LK, Woo J, et al. Sarcopenia in Asia: consensus report of the Asian Working Group for Sarcopenia. J Am Med Dir Assoc. 2014;15(2):95-101. doi:10.1016/j.jamda.2013.11.025

18. Lee HK, Lee BH. The epidemiology of alcohol use disorders. J Korean Diabet. 2012;13(2):69-75. doi:10.4093/jkd.2012.13.2.69

19. Schneeweiss S, Wang PS, Avorn J, Glynn RJ. Improved comorbidity adjustment for predicting mortality in Medicare populations. Health Serv Res. 2003;38(4):1103-1120. doi:10.1111/hesr.2003.38.issue-4

20. Tak YJ, Lee JG, Yi YH, et al. Association of handgrip strength with dietary intake in the Korean population: findings based on the Seventh Korea National Health and Nutrition Examination Survey (KNHANES VII-1), 2016. Nutrients. 2018;10(9):E1180. doi:10.3390/nu10091180

21. Goodpaster BH, Park SW, Harris TB, et al. The loss of skeletal muscle strength, mass, and quality in older adults: the health, aging and body composition study. J Gerontol A Biol Sci Med Sci. 2006;61 (10):1059-1064. doi:10.1093/gerona/61.10.1059

22. Kim S, Kim M, Min J, et al. How much intake of sodium is good for frailty?: the Korean Frailty and Aging Cohort Study (KFACS). J Nutr Health Aging. 2019;23(6):503-508. doi:10.1007/s12603-019-1198-6

23. Cohn JN, Kowey PR, Whelton PK, Prisant LM. New guidelines for potassium replacement in clinical practice: a contemporary review by the National Council on Potassium in Clinical Practice. Arch Intern Med. 2000;160(16):2429-2436. doi:10.1001/archinte.160.16.2429

24. Struijk EA, Banegas JR, Rodríguez-Artalejo F, Lopez-Garcia E. Consumption of meat in relation to physical functioning in the Seniors-ENRICA cohort. BMC Med. 2018;16(1):50. doi:10.1186/ s12916-018-1036-4

25. Murtaugh MA, Beasley JM, Appel LJ, et al. Relationship of sodium intake and blood pressure varies with energy intake. Hypertension. 2018;71(5):858-865. doi:10.1161/HYPERTENSIONAHA.117.10602

26. Drenjancevic-Peric I, Jelakovic B, Lombard JH, Kunert MP, Kibel A, Gros M. High-salt diet and hypertension: focus on the renin-angiotensin system. Kidney Blood Press Res. 2011;34 (1):1-11. doi:10.1159/000320387

27. Grikinienè J, Volbekas V, Stakisaitis D. Gender differences of sodium metabolism and hyponatremia as an adverse drug effect. Medicina (Kaunas). 2004;40(10):935-942. 
28. Haizlip KM, Harrison BC, Leinwand LA. Sex-based differences in skeletal muscle kinetics and fiber-type composition. Physiology (Bethesda). 2015;30(1):30-39. doi:10.1152/physiol.00024.2014

29. O'Donnell M, Mente A, Yusuf S. Sodium intake and cardiovascular health. Circ Res. 2015;116(6):1046-1057. doi:10.1161/CIRCRESAHA. 116.303771

30. Rush TM, Kritz-Silverstein D, Laughlin GA, Fung TT, BarrettConnor E, McEvoy LK. Association between dietary sodium intake and cognitive function in older adults. J Nutr Health Aging. 2017;21 (3):276-283. doi:10.1007/s12603-016-0766-2
31. Drake-Holland AJ, Noble MI. Should we now abandon the low-salt diet? QJM. 2011;104(12):1103-1106. doi:10.1093/qjmed/hcr124

32. Cogswell ME, Loria CM, Terry AL, et al. Estimated $24 \mathrm{hr}$ urinary sodium and potassium excretion in US adults. JAMA. 2018;319 (12):1209-1220. doi:10.1001/jama.2018.1156
Clinical Interventions in Aging

\section{Publish your work in this journal}

Clinical Interventions in Aging is an international, peer-reviewed journal focusing on evidence-based reports on the value or lack thereof of treatments intended to prevent or delay the onset of maladaptive correlates of aging in human beings. This journal is indexed on PubMed Central, MedLine, CAS, Scopus and the Elsevie
Bibliographic databases. The manuscript management system is completely online and includes a very quick and fair peer-review system, which is all easy to use. Visit http://www.dovepress.com/ testimonials.php to read real quotes from published authors. 